\title{
EVOLUTION OF GRAPHIC SYMBOLS FOR CARDIOVASCULAR SOUNDS AND MURMURS
}

\author{
BY \\ HAROLD N. SEGALL \\ From the Department of Medicine, McGill University, and the Montreal General and the Jewish General Hospitals
}

Received June 12, 1961

Graphic symbols for heart sounds and murmurs first appeared in 1861 in an article entitled A Short Acçount of Cardiac Murmurs, by William Tennant Gairdner. Laennec (1837), who first explored auscultation as a clinical diagnostic method, discovered a vast number of new facts which called for precise description. With faith in the rich vocabulary of his native language, aided by his good knowledge of Latin and Greek, he used words of language to describe what he heard. Whenever possible, he chose onomatopeic words, such as soufflet, claquement, crie de cuir, etc. On one occasion, in 1824, he resorted to musical notation to assist words in describing the rhythm of a venous hum heard in the supra- and infra-clavicular regions of a lady who showed also signs of pulmonary phthisis in the following words: "En explorant la région sous-clavière droite, j'entendis un bruit de soufflet médiocrement intense. Je voulus voir s'il n'existait pas aussi dans la carotide du même côté. Je fus étrangement surpris d'entendre, au lieu du bruit de soufflet, le son d'un instrument de musique exécutant un chant assez monotone, mais fort distinct et susceptible d'être noté. Je crus d'abord que l'on faisait de la musique dans l'appartement situé au dessous de celui dans lequel nous étions. Je prêtai l'oreille attentivement; je posai le stéthoscope sur d'autres points: je n'entendis rien. Après m'être assuré que le son se passait dans l'artère, j'étudiai le chant: il roulait sur trois notes formant à peu près un intervalle d'une tierce majeure; la note la plus aiguë était fausse et un peu trop basse, mais pas assez pour pouvoir être marquée d'un bémol. Sous le rapport de la valeur ou durée, ces notes étaient assez égales entre elles: la tonique seule était de temps en temps prolongée, et formait une tenue dont la valeur variat. Je notai en conséquence ce chant ainsi qu'il suit:

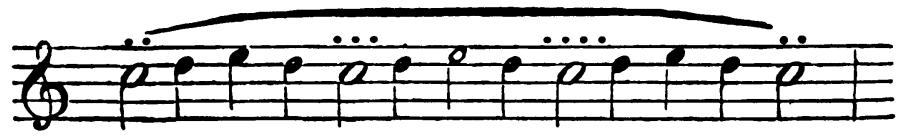

FIG. 1.-Reproduced from Laennec (1837). The musical notation is integrated into the description of the venous hum in Laennec's text. Laennec assumes that the murmur is produced in the carotid artery, but most likely it is the familiar venous hum produced in the jugular vein.

“Le son était faible et comme éloigné, un peu aigre et fort analogue à celui d'une guimbarde, avec la différence que cet instrument rustique ne peut exécuter que des notes pointées, et qu'ici, au contraire, toutes les notes étaient coulées. Le passage, d'une note à une autre était évidemment déterminé par la diastole..."

This marks the first use of any kind of symbol for sound applied in describing a cardiovascular murmur. It remained for Gairdner to introduce the systematic representation of sounds and 
murmurs by graphs designed mainly to show quantitatively the time relations and to some extent the relative loudness. According to Gibson (1912), no earlier record of such graphic symbols exists. He states, "Gairdner for the first time made use of diagrams in order to represent the relation of the audible and tangible phenomena to the physiological movements and sounds of the heart. This was quite a new departure and was one which has been followed by every teacher of medicine since his introduction of this method."

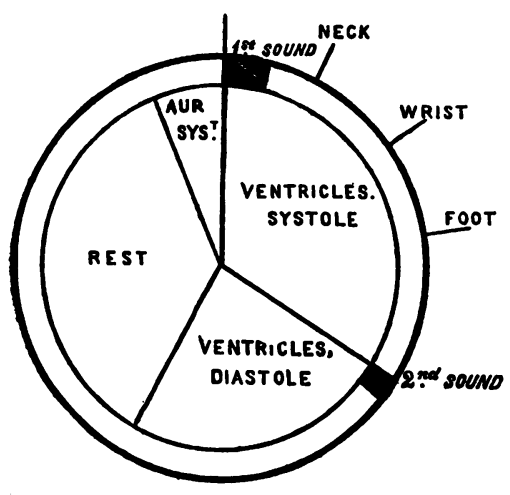

FIG. 2.--Reproduced from Gairdner (1861-62). The symbols for the heart sounds indicate the first as longer but not louder than the second.

Gairdner presents three effective illustrations in this article: One (Fig. 2) clearly defines the relation between the two heart sounds and the events of the cardiac cycle; in this graph, he shows the first sound as longer but not louder than the second. Another (Fig. 3) explains the changes in duration of diastole as the heart rate slows from what appears to be 150 a minute to 60 . He measures time along the abscissa. One may speculate that this convention came into being as the result of Ludwig's (1847) invention of the kymograph. The blood pressure record consisted of a graph in which the abscissa denoted duration and the ordinate, amplitude of the pulse.

Gairdner represents loudness along the ordinate. The taller line for the first sound indicates its relatively greater loudness than the second sound shown by the smaller line. These single lines offer no suggestion as to the duration of the sounds. The third graph (Fig. 4) summarizes on one page what he says in ten pages of words. He described murmurs with parallel vertical lines which suggest sound waves. By 1861 , sound waves such as the vibrations of a tuning fork or of a violin string had already been recorded on a kymograph, and this could have inspired the use of the parallel vertical lines to describe murmurs. Decrescendo and crescendo features which are quantitative aspects of the murmurs are reflected by the height of the lines. More widely-spaced lines may suggest lower vibration frequency, and the more closely-packed lines higher frequency. In the light of current knowledge, these features are not precisely represented in Gairdner's graphs. The mitral diastolic murmur should be drawn with widely-spaced lines.

Marey (1881), a great partisan of the graphic method, represented the two heart sounds by solid rectangles (Fig. 5). Open rectangles appeared in the publications of Gairdner's three younger contemporaries, John Wyllie (quoted by Hutchison and Rainy, 1917), Byrom Bramwell (1884), and George Gibson (1898). This evolution of the symbols for heart sounds from a single vertical line to an open rectangle was a natural step in making a graph that describes what is heard more precisely. The vertical lines can demonstrate relative loudness, but they omit any indication of heart sound duration which the rectangles do show (Fig. 6 and 7). The open rectangle functions much better than the solid because it permits superimposing the symbol for a murmur on the entire area or on a part of the heart sound symbol. In a pattern of sounds and murmurs, the thud-like quality of the sounds is clearly reflected in the rectangles and the noise of a different kind, which is the murmur, is similarly obvious in the waves of parallel vertical lines. The early phase of the mitral diastolic murmur is erroneously represented as crescendo in Bramwell's drawing (Fig. 7). The relative duration of the first and second sounds and of the interval between them makes the first sound much longer than it is now known to be. The graphs do not indicate the differences in loudness of the two sounds commonly associated with mitral stenosis in the presence of a crescendo presystolic murmur. The ordinate represents relative loudness in the murmur but is not used for the same purpose in describing the sounds.

The rectangles used by Wyllie and Bramwell have the defect of omitting what Gairdner's simple lines do show, namely, relative loudness. Gibson took some cognizance of this but in an inconsistent manner (Fig. 8). He attempted to suggest pitch and quality by varying the shape of the top 
of the rectangle. However, in depicting the patterns of sounds and murmurs for mitral stenosis, he fails to indicate the relative loudness of the heart sounds expected in the presence of such a decrescendo-crescendo murmur. In common with Wyllie, he does not indicate the isometric diastolic period of quiet. Nevertheless, his modifications of some symbols to indicate relative

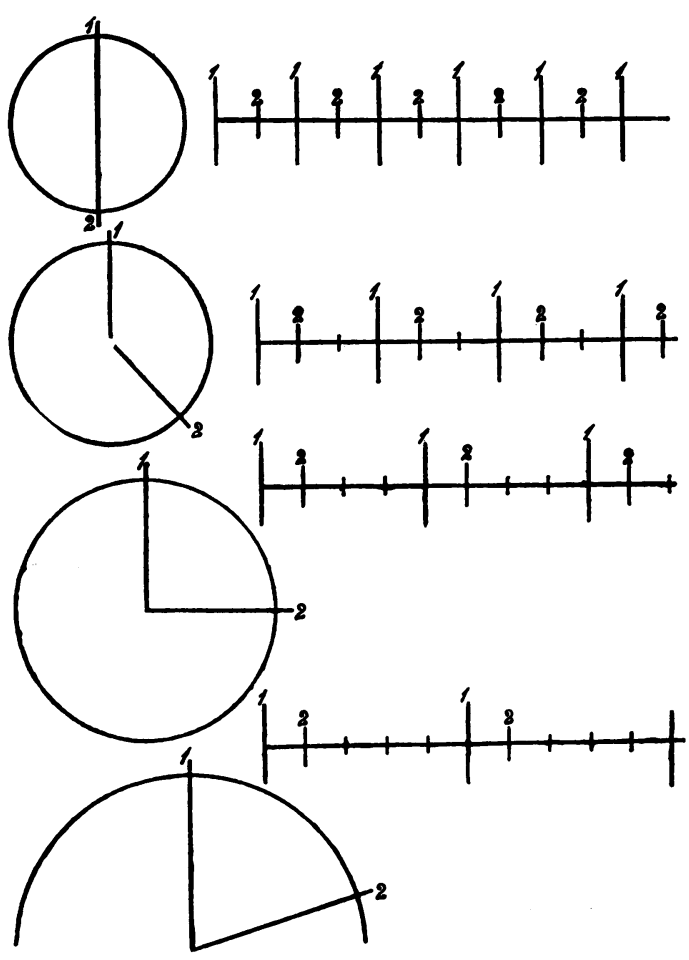

FIG. 3.-Reproduced from Gairdner (1861-62). In this graph Gairdner emphasizes the quantitative representation of time along the abscissa. Incidentally, he shows the first sound as louder than the second but omits any attempt to show difference in duration of the sounds; Fig. 2 indicates he was aware that the first sound is usually longer than the second.
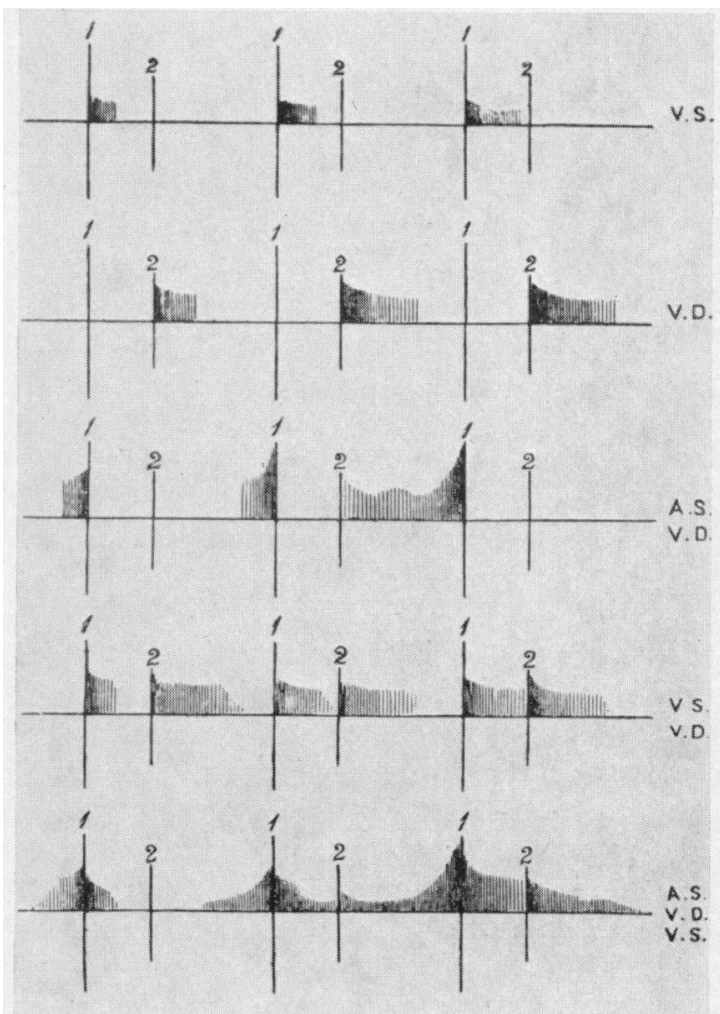

FIG. 4.-Reproduced from Gairdner (1861-62). The duration and relative loudness of various murmurs and especially their time relations are depicted in these graphs. $\mathrm{VS}=$ ventricular systole, $\mathrm{VD}=$ ventricular diastole, $\mathrm{AS}=$ auricular systole. The vibration frequency of the murmurs is not clearly represented by variations in the spaces between lines. The relative loudness of the sounds shown as the same for all cases indicates that they were casually written and do not reflect what is heard in association with these murmurs. Gairdner did not systematically represent variations in loudness and duration of the sounds nearly as well as he did of the murmurs.
1*r bruit.
$2^{e}$ bruit.
1er bruit.
$2^{\bullet}$ bruit.

\section{Pelit silence. \\ Grand silence. Petit \\ Grand silence. \\ Pulsation.}

Pulsation.

FIG. 5.-Reproduced from Marey's book (1881). Marey, using solid rectangles, indicates that the first is louder than the second sound but represents them as of equal duration. The diagram is schematic and does not achieve precise description of what is heard. It is of interest because it represents the earliest use of rectangles instead of thin lines for the sounds. 


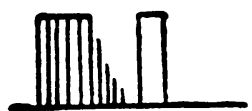

Sistolic

(regurgitant)

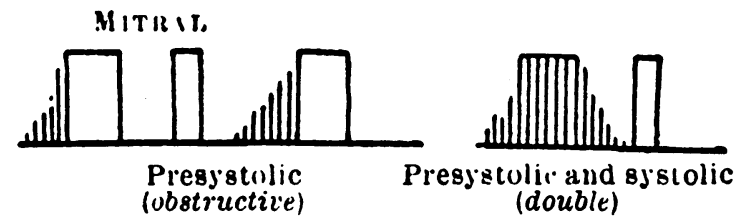

Diastolic mitral

Diastolic and presystolic

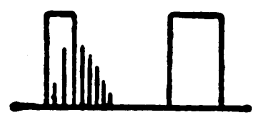

Rare forms of mitral

olsitructive illurmurs

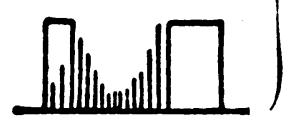

Mitral murmurs. (After Wyllie.)

Fig. 6.-Reproduced from Hutchison and Rainy (1917). The rectangles show differences in duration but not in loudness of the sounds. The parallel lines show differences in both loudness and duration of the murmurs but do not suggest differences in quality. The decrescendo early mitral diastolic murmur is shown as accompanying the end of the second sound. In the light of subsequent knowledge, this is now recognized as inaccurate. The graphs reveal the inaccuracy more definitely than a description in words of language.

loudness of the sounds draws attention to the defect in the illustrations presented by Wyllie and by Bramwell. All these authors seem to have this in common: they wrote the symbols rather casually, i.e. not with a conscious effort to measure and to demonstrate relative loudness and duration of the sounds and murmurs as precisely as the graphic symbols can make this possible.

A clue to the earliest use of graphic symbols such as those of Gairdner in America appears in the letter addressed to Gairdner by Henry T. Bowditch in 1862 (Gibson, 1912): "Dear Sir, This note will be delivered to you by my young friend Dr. Cutter-of this State - who intends to spend a few months in Europe. May I ask you to allow him to visit with you the wards under your charge? I read with interest all the papers presented by yourself to the medical journals. Very recently I saw your introductory remarks to your clinical course. In these you refer to certain diagrams to be used by students and practitioners. May I ask you to give Dr. C. one of them for me-in order that I may have it reprinted for the use of our students?" At the turn of this century, Cabot (Sprague, 1954) used open rectangles for sounds and parallel vertical lines for murmurs in the style of Wyllie, Bramwell, and Gibson but with little more attention to relative loudness. The route by which Cabot came to adopt the use of these symbols has not yet been met with.

One day in July 1926, the author was reading some books on cardiology to trace the evolution of Sir James Mackenzie's emphasis on symptoms rather than signs in thinking about heart disease. As he turned the pages of Bramwell's book, the illustrations of heart sounds and murmurs caught his eye, perhaps because he was at that time concerned about devising a form on which to write clinical notes in the new Cardiac Clinic which was to be organized at the Montreal General Hospital. He modified Bramwell's symbols to make them more precisely quantitative (Segall, 1932). At first, he used words or initials to indicate the area of auscultation. In 1930, a new feature was added, the silhouette of the heart as a map to indicate the areas at which the stethoscope was held while listening. The symbols were written on horizontal lines drawn from dots which marked these areas. Diagrams of the chest had long been used by lung specialists to indicate the positions of clinical signs. Dr. N. Bethune had produced a booklet of such diagrams on gummed pages which could be torn out and stuck on a page of the clinical record. In emulation of this technique, a booklet of heart sound charts was produced in 1934 .

The most recent step in the evolution of this method of writing quantitative symbols to describe cardiovascular sounds and murmurs while listening was made possible by a statistical analysis of 


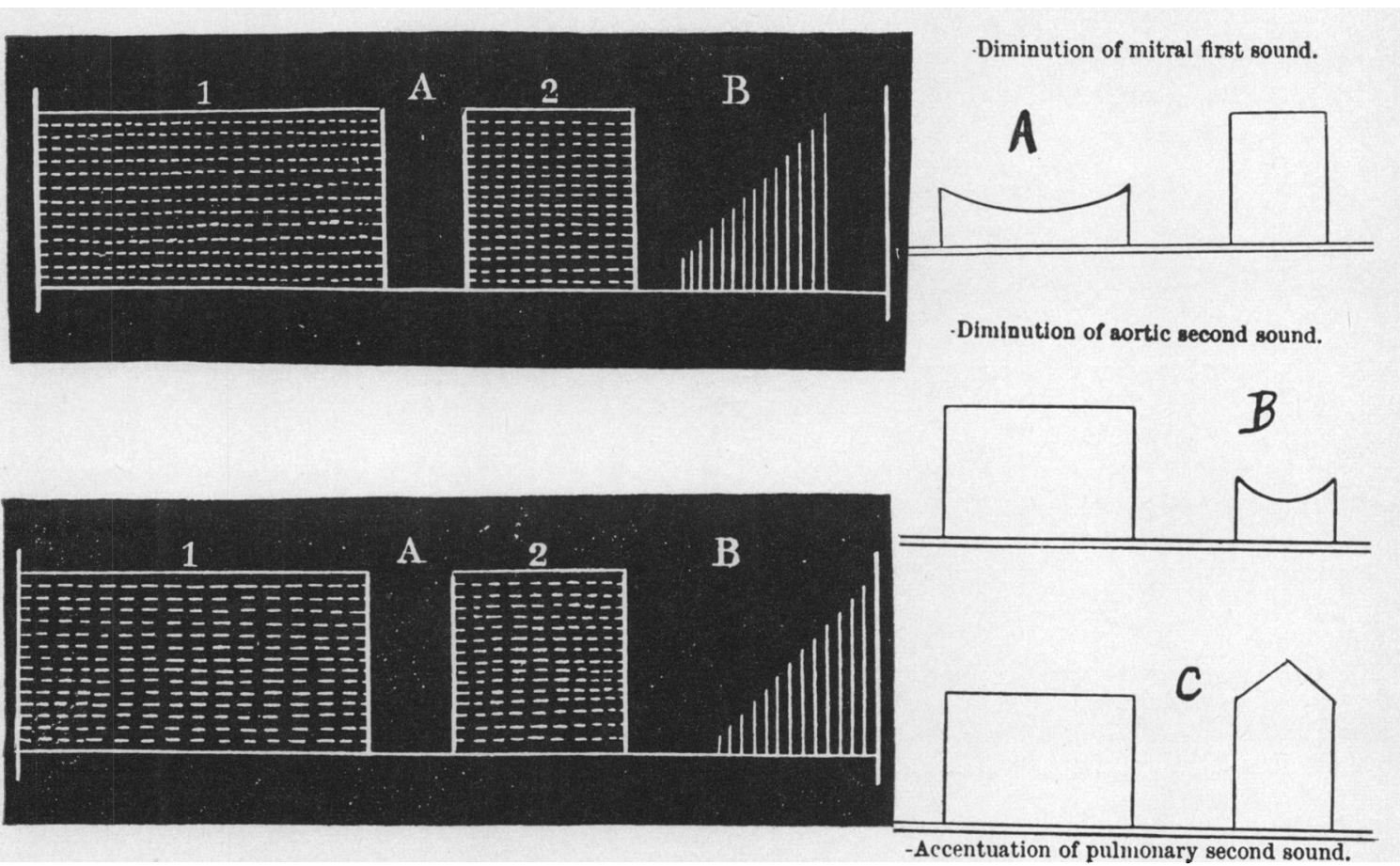

FIG. 7.-Reproduced from Bramwell's book (1884). These two graphs were FIG. 8.-Three diagrams reproduced from selected from the many in Bramwell's book to show that he did recognize the isometric relaxation pause between the end of the second sound and the early phase of the diastolic murmur (above). He refers to this murmur as a rarely observed entity, the more usual type related to mitral stenosis being the presystolic crescendo murmur (below). See text. Gibson's book (1898). (A) Diminution of mitral first sound. (B) Diminution of aortic second sound. (C) Accentuation of pulmonary second sound (see text). These indicate that he was aware of the need for demonstrating differences in both duration and loudness of the sounds by the graphs.

observations on 100 normal young men to find the range and modal pattern of normal sounds. The composite modal pattern derived from this study (Segall, 1962) was adopted as the standard for normal at each area of auscultation (Fig. 9). In 1949, these symbols were printed faintly on the heart sound chart to serve as guides in writing the symbols for what is being heard in a given case (Fig. 9, 10, 11, 12). A special advantage of this technique is that a global pattern of heart sounds and murmurs at all areas of auscultation is composed as the observer analyses what he hears and synthesizes the description as he writes.

Fig. 11 shows that the oscillographic phonocardiogram confirmed the effect of the prolonged A-V conduction time in separating the end of the mitral diastolic murmur from the beginning of the first sound. This interval of time was found to be longer at the left border of the sternum between the fourth and sixth intercostal spaces than at the apex (Fig. 10). This too was confirmed and suggests the possibility of tricuspid stenosis. The flexibility of the method of writing quantitative symbols is particularly well illustrated in showing the blowing diastolic murmur heard at the left border of the sternum near the fourth intercostal space in the sitting position as it begins immediately after the second sound and does not entirely mask the opening snap. The oscillographic phonocardiogram failed to record this murmur. It might have been recorded by greatly increasing magnification of the sounds so that it would appear in the record made with the 250 cycle per second filter, but this would greatly distort the remaining elements of the record. It was readily audible and the quantitative symbols depict it with a high degree of precision. The Korotkoff sounds are louder 

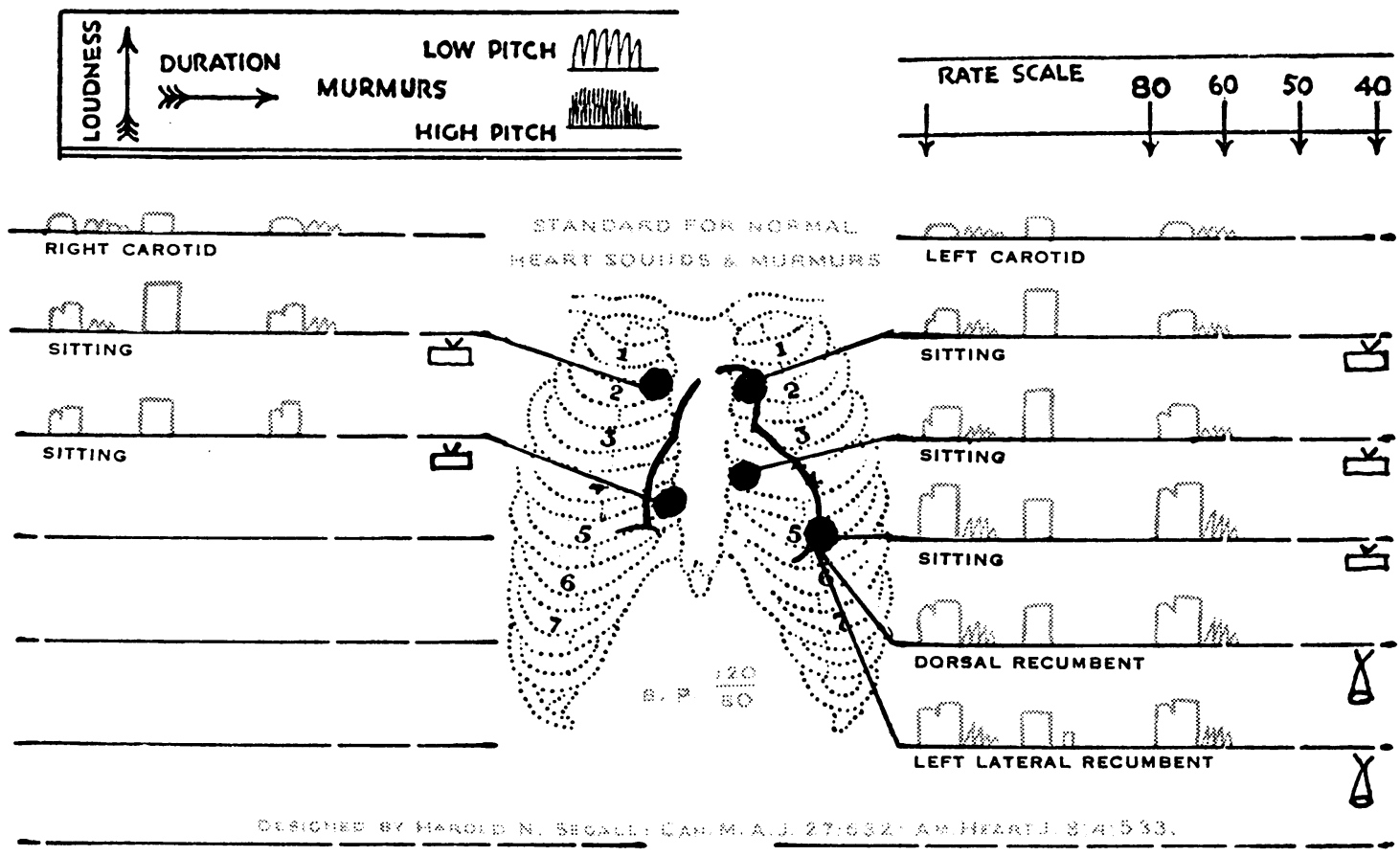

FIG. 9.-The heart sound chart for writing quantitative symbols for heart sounds and murmurs while listening. More precise instructions for the use of this chart as an integral function of auscultation of the heart is to be found in Segall (1959). The basic rules of the method appear in the left-hand upper corner. Loudness is described by the ordinate and duration by the abscissa. A rectangle represents a sound. Quality is implied since a short, sharp sound has a high-pitched quality and a relatively long sound, a low-pitched quality. Special qualities such as amphoric, ringing, etc., are indicated by writing the word near the symbol. Loudness and duration of murmurs are also described along the ordinate and the abscissa respectively. Gross variations in pitch are shown by writing widely separated waves for low-pitched and closely packed lines for high-pitched murmurs. The faintly printed symbols represent the composite modal pattern of normal. These guide in writing symbols for what is being heard. Note the arbitrary rate scale and the symbols to indicate the type of stethoscope chest piece used.

than the average normal, suggesting some degree of aortic regurgitation. The systolic murmur at the aortic and pulmonic areas, as well as over the carotid and suprasternal regions, is lower pitched than at the apex suggesting that there is both aortic stenosis and mitral regurgitation. None of the murmurs were heard over the back but the heart sounds could be detected as faintly audible with the first louder than the second sound; the latter was inaudible on the right side.

These comments about the global pattern of heart sounds and murmurs mention only some highlights. A detailed description would be tedious to write and more tedious to read. The pattern of symbols can be read almost at a glance and observations made at different times readily compared.

The greatest difference in Fig. 11 appears in recording the systolic murmur, which has a very low amplitude in the oscillographic phonocardiogram but is a loud murmur about half the loudness of the first sound as heard and described by the quantitative symbols. To record this high-pitched systolic murmur it would be necessary to increase the volume of magnification to such an extent that the other features would be greatly distorted and the graph would not afford a satisfactory impression of the entire pattern of heart sounds and murmurs. The mitral diastolic murmur is shown to end about $0.05 \mathrm{sec}$. before the beginning of the first sound in both records but this can be measured more precisely in the oscillographic phonocardiogram. The timing of heart sounds and murmurs is relatively more precise with the electronic method. Description of the relative 


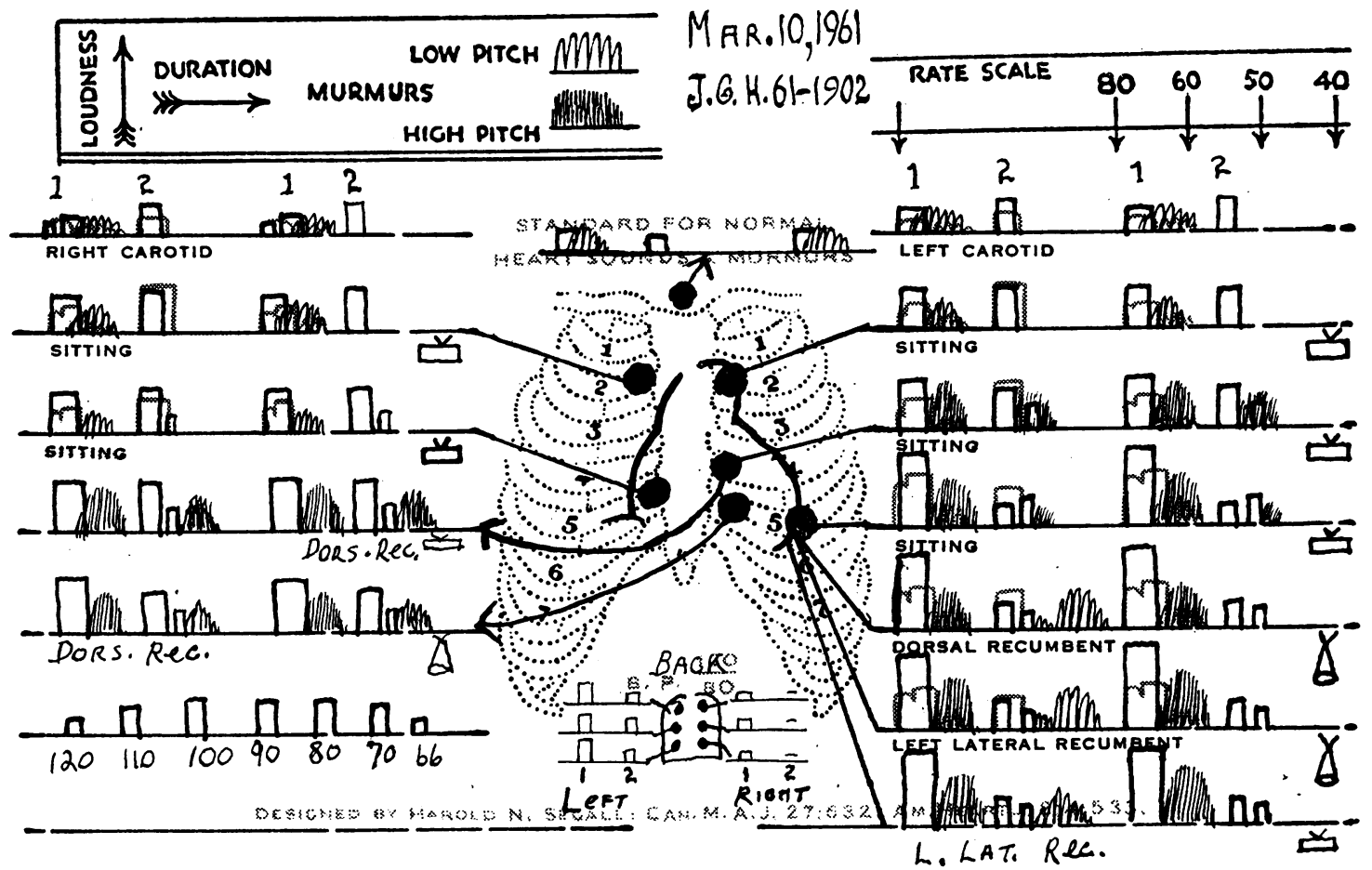

Fig. 10.-The heart sounds and murmurs in a woman aged 48 who had valvotomy for mitral stenosis in 1955 at the age of 42 and who had been observed by the author since she was 15 years old. This record was made a few minutes before the oscillographic phonocardiogram shown in Fig. 11 was recorded. The task of listening and writing the quantitative symbols to describe what is heard was completed in six minutes. The oscillographic phonocardiogram was recorded at each of the five præcordial areas of auscultation. See text.

loudness, pitch, and quality of the sounds and murmurs is more satisfactory in the quantitative symbols.

Ravin (1958) has written the first book on auscultation of the heart in which quantitative symbols, according to the method described by Segall in 1933, are used. The 1949 modifications appear in later publications (Segall, 1954 and 1959). Ravin's very good book is compact but rich in details: had he used words to describe all that appears in the symbols, the size of the book would be considerably larger. In a book on Cardio-Charting, the first treatise devoted entirely to a method of describing cardiac auscultatory signs by symbols, Briskier (1957) presents strong arguments in favour of graphic symbols. He has chosen to use solid rectangles, abandoning the advantages of open rectangles for sounds and parallel vertical lines for murmurs. The technique includes using two colours, red for systole and blue for diastole, as well as a number of signals such as arrows, initials, serrated edges on the solid rectangles and, occasionally, round rather than rectangular figures.

Einthoven and Geluk (1894) published the first electric phonocardiograms. These seem to have inspired very few to make use of schematic drawings of such waves as symbols for cardiovascular sounds and murmurs. Wiggers' (1949) book on physiology contains one figure in which such graphs are used. No author has used diagrams of the electric phonocardiogram more liberally or effectively than Luisada in his numerous articles and books. In one diagram in which he and Aravanis (1957) refine the difference between a sound wave that is recorded by an instrument and the thud-like sound that is heard by the human ear, they wisely display the latter by a diagram of an open rectangle (Fig. 13). 




Fig. 11. The oscillographic record was reduced to 0.8 of its normal size. Time: 1 sec. $=8 \mathrm{~mm}$. The quantitative symbols (E) are about double the size of those shown in Fig. 10.

Comparison of heart sounds and murmurs described by quantitative symbols and recorded by oscillographic phonocardiogram (Schwartzer Multi-Channel Apparatus). (A) with $250 \mathrm{cps}$ filter; (B) with $70 \mathrm{cps}$ filter; (C) with no filter; and (D) lead II. (E) shows quantitative symbols copied from Fig. 10 for sounds and murmurs heard at the apex in the dorsal recumbent position with the bell stethoscope. (At) indicates an artefact immediately after the opening snap. Both the record with the $70 \mathrm{cps}$ filter and the quantitative symbols show that the first sound has the greatest amplitude and that the relative loudness of the first and second sounds is similar in the two records. The ratio between the amplitude of the first sound and of the tallest wave in the mitral diastolic murmur is about 2 to 1 in both records. The relative loudness of the opening snap as compared with the second sound is similar in both records. See text.

Lenègre (1948) uses short vertical lines for the first and second sounds and diagrams of electrophonocardiograms with some poetic licence to describe murmurs. His illustrations include a good representation of the pericardial friction rub to indicate its time relations and superficial quality. Some illustrations of the decrescendo and crescendo murmur of mitral stenosis are made with rather widely separated waves which suggest the low vibration frequency. However, Lenègre does not describe any systematic method for the use of symbols for sounds and murmurs in making clinical notes. Holldack and Wolff in their recent books (1958, 1959, and 1960) show graphic symbols 

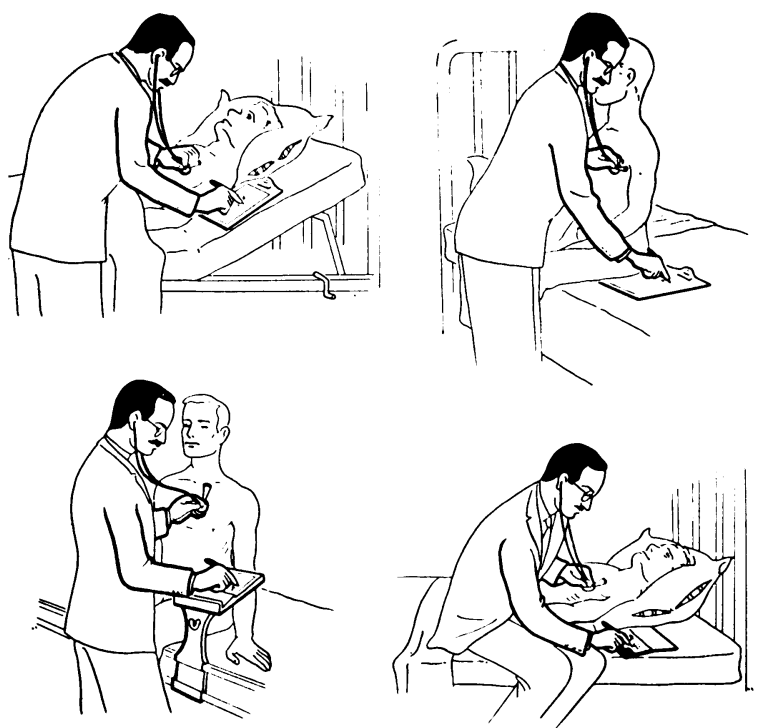

FIG. 12.-These figures show the postures adopted by the listener so that he may be well relaxed and comfortable while listening and writing. The four different clinical positions are the usual ones. The listener must be at the left side of the patient to avoid a clumsy posture for writing. In the lower left-hand corner the patient is sitting on an office examining table which is equipped with a sliding writing shelf at a convenient height. In the remaining three figures, the patient is on a bed, a high hospital bed in the upper two and a low bed of the type found in homes in the lower right-hand corner.
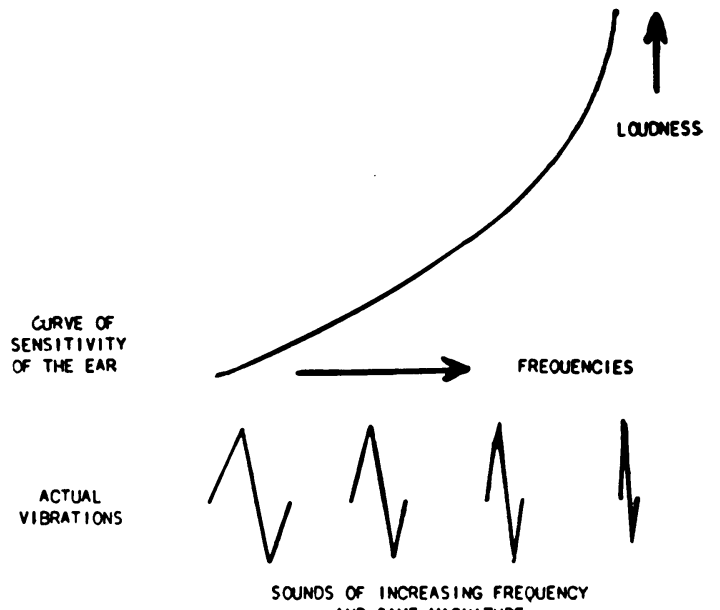

AND SAME MAGNITUDE

$\operatorname{MHAT}_{\text {MEARD }}$

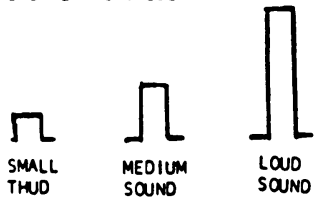

Fig. 13.-(From Luisada and Aravanis.) To show that high-pitched sounds are heard as louder sounds than represented by the amplitude of recorded vibrations. Open rectangles effectively depict the sounds as heard.

that bear a close resemblance to the quantitative symbols introduced by us: they also use a few diagrams of phonocardiograms.

Rushmer (1955) coined the word sonvellogram to describe what amounts to an envelope of the group of waves recorded in an electric phonocardiogram. The resultant graphs beg to be adopted as written symbols for sounds. They closely resemble open rectangles. To indicate murmurs, Rushmer applies solid figures to the sides of these diagrams. His other diagrams include schematic phonocardiograms.

Leatham (1958) mentions that, in teaching, drawings of phonocardiograms are no less effective than displaying the sounds on a fluorescent screen attached to the phonocardiograph. However, to illustrate sounds, he uses symbols of the type introduced by Gairdner a hundred years ago. The single lines for sounds omit any suggestion as to the duration of these elements of the cardiac cycle. Holldack and Wolff in their books on auscultation of the heart include a few diagrams based on phonocardiograms and some also in which rectangles represent sounds.

E. J. Marey (1878) wrote the following as the first few sentences in the introduction to his book, La Méthode Graphique: "Science has before it two obstacles that impede its advance. There is first the inadequacy of the senses to discover truths and then the insufficiency of language to describe and transmit the truths we have acquired. The object of scientific methods is to remove these obstacles. The graphic method attains this double purpose better than any other. In fact, in delicate studies, it catches nuances that would escape other methods of observation; and if it is a question of describing the progress of a phenomenon, then it reveals the stages with a clarity that language does not possess." He had in mind graphic methods that involved instruments like the kymograph of his day and the galvanometers with photographic or direct writing attachments of recent times. However, his views remain applicable to the use of written graphic symbols to 
describe cardiovascular sounds and murmurs. As long as the stethoscope remains his vademecum the physician will have the task of describing what he hears. McKusick (1958), in the course of composing a very good and erudite book on cardiovascular sound, wrote: "In recording the findings of auscultation, a crude diagram can be worth a thousand words. The oscillograph phonocardiogram has not been able to fill the role. Potentially, the spectral phonocardiogram might."

The method that William Tennant Gairdner introduced 100 years ago has evolved very slowly. It shared the ups and downs of interest in auscultation of the heart during the past century. The recent revival of a deep interest in this aspect of clinical medicine has been stimulated by rapid progress in cardiac surgery. The method of writing quantitative symbols to describe what is heard while listening, a direct descendant of Gairdner's invention, may now become an integral part of the art and science of cardiac auscultation.

\section{REFERENCES}

Bramwell, Byrom (1884). Diseases of the Heart and Thoracic Aorta. Young, J. P., Edinburgh.

Briskier, A. (1957). Cardio-Charting, Universal Method of Recording Heart Auscultation. Macmillan, New York.

Einthoven, W., and Geluk, M. A. J. (1894). " "Die Registrierung der Herztone," Pfluger's Arch. ges. Physiol., 57, 617.

Gairdner, W. T. (1861-62). "A Short Account of Cardiac Murmurs." Edinburgh med. J., 7, 438.

Gibson, G. A. (1898). Disease of the Heart and Aorta. Young, J. Pentland, Ed., Macmillan, New York. (1912). Life of Sir William Tennant Gairdner. James Maclehose and Sons, Glasgow, p. 682.

Holldack, K. (1959). Lehrbuch der Auskultation und Perkussion. George Ghieme, Stuttgart.

-, and Wolf, D. (1958). Atlas und Kurzgefasstes Lehrbuch der Phonokardiographie. Georg Thieme, Stuttgart.

- (1960). Herzschall-Fibel. Georg Thieme, Stuttgart.

Hutchison, R., and Rainy, H. (1917). Clinical Methods. Cassell and Co. Ltd., London and New York, p. 165.

Laennec, R. T. H. (1837). Traité de L'Auscultation. J. S. Chaudé, Libraire-editeur, pp. 76-78.

Leatham, A. (1958). "Auscultation of the Heart." Lancet, 2, 703.

Lenégre, J. (1948). Séméiologie cardio-vasculaire. J. B. Baillière, Paris, pp. 63-86.

Ludwig, C. (1847). Arch. Anat. Physiol. wissensch. Med., Berl. 261.

Luisada, A. A., and Aravanis, C. (1957). Med. Clin. North Amer., 41, 235.

Marey, E. J. (1881). La Circulation du Sang a L'Etat Physiologique et dans les Maladies. G. Masson, Editeur, Libraire de L'Académie de Médecine, Paris, p. 124.

- (1878). La Methode Graphique dans les Sciences Expérimentales et principalement en Physiologie et en Médecine. G. Masson, Editeur, Libraire de L'Académie de Médecine, Paris.

McKusick, V. A. (1958. Cardiovascular Sound in Health and Disease. Williams \& Wilkins, Baltimore, p. 75.

Ravin, A. (1958). Auscultation of the Heart. The Year Book Publishers, Chicago.

Rushmer, R. F. (1955). Cardiac Diagnosis. A Physiologic Approach. W. B. Saunders, Philadelphia \& London, p. 225.

Segall, H. N. (1932). Canad. med. Ass. J., 27, 632. (1933). Amer. Heart J., 8, 533.

(1962). "Heart sounds and murmurs in 700 normal subjects." J. Canad. med. Ass. (in press).

-, and Harris, M. (1954). Canad. med. Ass. J., 70, 416. Cardiology. Aldo Luisada, Ed., McGraw-Hill, Vol. 2, 3-105.

Sprague, H. B. (1954). Circulation, 9, 127.

Wiggers, C. J. (1949). Physiology in Health and Disease. 5th edit., Lea \& Febiger, Philadelphia, p. 667. 